\title{
Nuclear actin polymerization is required for transcriptional reprogramming of Oct4 by oocytes
}

\author{
Kei Miyamoto, Vincent Pasque, Jerome Jullien, and John B. Gurdon ${ }^{1}$ \\ Wellcome Trust, Cancer Research UK Gurdon Institute, University of Cambridge, Cambridge CB2 1QN, United Kingdom
}

\begin{abstract}
Amphibian oocytes can rapidly and efficiently reprogram the transcription of transplanted somatic nuclei. To explore the factors and mechanisms involved, we focused on nuclear actin, an especially abundant component of the oocyte's nucleus (the germinal vesicle). The existence and significance of nuclear actin has long been debated. Here, we found that nuclear actin polymerization plays an essential part in the transcriptional reactivation of the pluripotency gene Oct4 (also known as Pou5f1). We also found that an actin signaling protein, Toca-1, enhances Oct4 reactivation by regulating nuclear actin polymerization. Toca-1 overexpression has an effect on the chromatin state of transplanted nuclei, including the enhanced binding of nuclear actin to gene regulatory regions. This is the first report showing that naturally stored actin in an oocyte nucleus helps transcriptional reprogramming in a polymerization-dependent manner.
\end{abstract}

[Keywords: nuclear actin; transcriptional reprogramming; Xenopus oocyte; Oct4; Toca-1]

Supplemental material is available for this article.

Received November 12, 2010; revised version accepted March 16, 2011.

Differentiated cell states are stable. Once cell types are established, they hardly ever change to other cell types in normal development. However, several experimental approaches enable differentiated cells or nuclei to generate primitive embryonic cells that can redifferentiate into every cell type in a body. These include nuclear transfer (NT) to eggs/oocytes and induced pluripotent stem (iPS) cells (Gurdon and Melton 2008; Jaenisch and Young 2008). Mechanistic insights into these reprogramming processes are still elusive, although it is known that induced pluripotency can be initiated by defined transcription factors (Takahashi and Yamanaka 2006). Eggs/oocytes reprogram somatic cells more efficiently than the iPS procedure (Kim et al. 2010; Pasque et al. 2010). However, only a few reprogramming factors of eggs or oocytes have been identified so far (Tamada et al. 2006; Jullien et al. 2010).

Our aim is to identify reprogramming factors and mechanisms that eggs/oocytes naturally possess. However, reprogramming to pluripotency by eggs or iPS cells is a complicated process accompanied by many cell divisions. These often mask direct effects of reprogramming factors, and hence a stochastic model for iPS reprogramming has been proposed (Hanna et al. 2009; Yamanaka 2009|. Numerous cell divisions can also ob-

${ }^{1}$ Corresponding author.

E-MAIL j.gurdon@gurdon.cam.ac.uk; FAX 44-1223-334089.

Article is online at http://www.genesdev.org/cgi/doi/10.1101/gad.615211. Freely available online through the Genes \& Development Open Access option. scure the role of a reprogramming factor (Smith et al. 2010). Therefore, a system without cell division is desirable, especially for the purpose of revealing a mechanistic insight into reprogramming. One crucial event during reprogramming is the reactivation of silenced pluripotent/embryonic genes such as Oct4 (Boiani et al. 2002; Stadtfeld et al. 2008; Kim et al. 2009). A direct way to induce the transcriptional activation of Oct4 by oocyte factors is NT into Xenopus laevis oocytes at the germinal vesicle (GV) stage. In this type of NT, no cell division and no new protein synthesis is required before reprogrammed transcripts are detected (Byrne et al. 2003; Gurdon and Melton 2008), and the magnitude of transcription reaches a level equal to that of a fully transcribed state when certain cell types are used (Jullien et al. 2010).

In the current study, we focused on actin in an oocyte nucleus (nuclear actin) as a candidate reprogramming factor because our preliminary fractionation of reprogramming-related factors in oocyte extracts identified several nuclear actin-interacting proteins. Actin is a major component of the cytoskeleton and plays fundamental roles in many biological processes. However, large amounts of actin have been also found in a nucleus, including the GV of Xenopus oocytes (Clark and Merriam 1977). Recently, several groups have obtained evidence for actin having a functional role in the nucleus. This includes the finding that nuclear actin is engaged in transcription by all three RNA polymerases (Visa and Percipalle 2010), and the finding that many chromatin 
remodeling complexes are associated with actin (Zhao et al. 1998; Olave et al. 2002; Bettinger et al. 2004). However, it remains unclear whether nuclear actin is involved in gene reactivation, and its involvement in reprogramming processes has never been examined. Here, we found that nuclear actin polymerization, naturally occurring in the oocyte nucleus, is necessary for transcriptional reprogramming of Oct4 from transplanted somatic nuclei.

\section{Results}

Nuclear filamentous actin is formed in transplanted nuclei

Xenopus oocytes contain massive amounts of nuclear actin, which constitutes $\sim 6 \%$ of the total nuclear protein and is at a concentration of at least $2 \mathrm{mg} / \mathrm{mL}$ in the GV (Clark and Merriam 1977); the filamentous form of actin (F-actin) is observed in the GV (Bohnsack et al. 2006). We tested whether F-actin is formed in the nuclei of mouse cells transplanted into oocytes. A live-cell imaging method to visualize F-actin was developed in order to follow the dynamics of actin polymerization. Green fluorescent protein (GFP)-tagged F-actin probes based on the calponin homology domain of utrophin (GFP-UtrCH), which contains a F-actin-binding domain, faithfully marks the distribution of F-actin without changing the balance of actin assembly/disassembly (Burkel et al. 2007). GFP-UtrCH was expressed in oocytes by mRNA injection before NT (Fig. 1A).

GFP-UtrCH protein was detected in both the cytoplasm and the GV of oocytes (Supplemental Fig. S1A). In the GV, a meshwork structure of nuclear actin, as was reported by Bohnsack et al. (2006), was observed by the GFP-UtrCH probe (Fig. 1B). RFP-histone B4 or Cherryhistone $\mathrm{H} 2 \mathrm{~B}$ mRNA was coinjected to visualize the injected somatic nuclei. Nuclear actin was abundant around the injected nuclei (Supplemental Fig. S1B, white dotted area). Localization of actin at the nuclear periphery was observed at $3 \mathrm{~h}$ after NT, becoming stronger after further culture (Supplemental Fig. S1C, white arrows at $3 \mathrm{~h}$ and $16 \mathrm{~h})$. This actin localization overlapped with nuclear lamin B1, especially in the outer region of lamin B1 (Supplemental Fig. S2A, yellow color on the merge photo), indicating that perinuclear F-actin is formed on the nuclear envelope. This link is further supported by the observation that perinuclear actin localization disappeared in the area where the nuclear envelope had

A

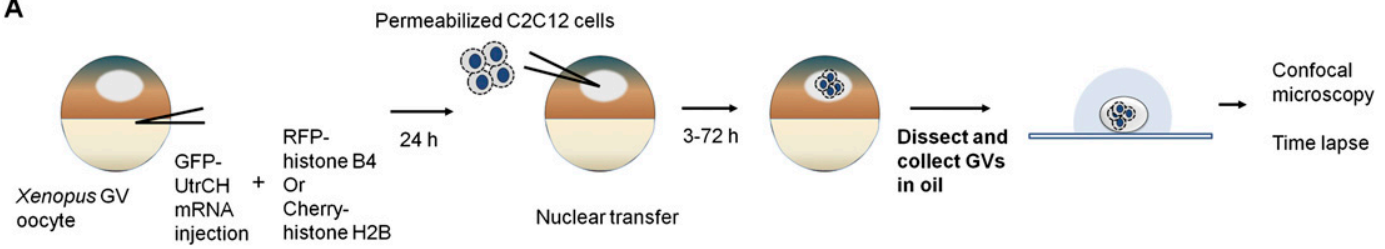

B

Nuclear periphery

Nuclear interior
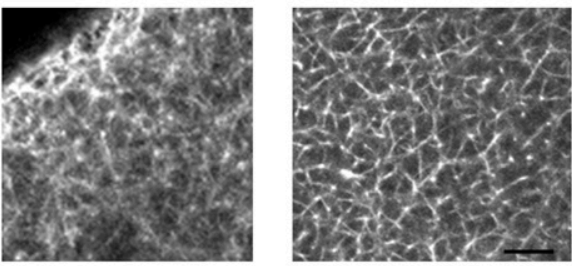

C

GFP-UtrCH

(F-actin)

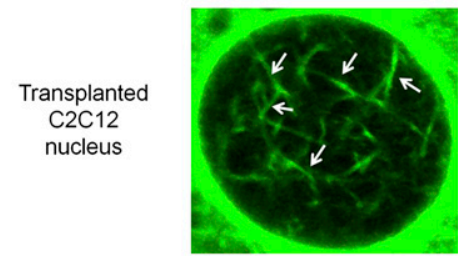

Cherry-histone $\mathrm{H} 2 \mathrm{~B}$ (Injected nucleus)

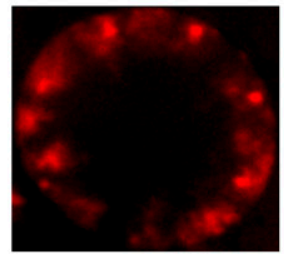

Merge

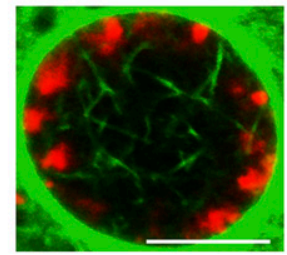

Figure 1. Visualization of nuclear F-actin. (A) Schematic diagram of the experimental strategy to visualize nuclear F-actin formed in transplanted nuclei. Injected nuclei cannot be observed without dissecting GVs. Dissected GVs can be maintained alive in mineral oil and are transparent enough to observe their interior structure by confocal microscopy. $(B)$ Nuclear F-actin in a Xenopus oocyte nucleus, visualized with GFP-UtrCH probes. A meshwork structure of nuclear F-actin is naturally formed in nucleoplasm. Bar, $5 \mu \mathrm{m}$. $(C)$ Nuclear F-actin is observed in injected nuclei. F-actin was labeled with GFP-UtrCH (green) and chromatin of injected nuclei was visualized with Cherry-histone H2B (red). Actin bundles in a transplanted nucleus are marked with white arrows. The image was taken $24 \mathrm{~h}$ after NT. Bar, $10 \mu \mathrm{m}$. 
broken down (Supplemental Fig. S2A, arrows). At $24 \mathrm{~h}$ after NT, filamentous nuclear actin was observed in the transplanted nuclei (Fig. 1C; Supplemental Fig. S1C, red arrows at $24 \mathrm{~h}$ ). Actin bundles were formed inside the circular chromatin (Fig. 1C, arrows), and actin filaments around and in the transplanted nuclei were mobile (Supplemental Movie S1).

We next asked whether differences in the donor nuclear states affected nuclear actin formation. The nuclei of embryonic stem (ES) cells were injected as representative of undifferentiated cells. ES nuclei swelled more easily than $\mathrm{C} 2 \mathrm{C} 12$ nuclei and were more extensively dispersed. Slightly more abundant actin filaments were observed in ES nuclei than in C2C12 nuclei (Supplemental Fig. S2B). This indicates that nuclei of ES cells, which have the greatest transcriptional plasticity, exhibit abundant nuclear actin formation when transplanted to oocytes.

To confirm that GFP-UtrCH faithfully recognizes F-actin, GVs with transplanted nuclei were fixed and stained with phalloidin-TRITC, which specifically marks F-actin. Phalloidin staining resulted in a pattern of F-actin formation similar to that visualized by GFP-UtrCH probes (Supplemental Fig. S3A). As a control, F-actin in cultured C2C12 cells before NT was also stained by the same method, but such nuclear F-actin formation was not observed (Supplemental Fig. S3B). In conclusion, F-actin is present in nuclei transplanted into Xenopus oocytes, although it takes $\sim 24 \mathrm{~h}$ to see a detectable level of nuclear F-actin. This delay in appearance of nuclear actin may be because transplanted somatic nuclei have inherited a mechanism to export actin (Stuven et al. 2003), and/or because no active import mechanism for nuclear actin exists in injected nuclei. The strong perinuclear localization of nuclear actin might reflect this active export (Supplemental Fig. S1C). More interestingly, the timing of nuclear actin appearance is correlated with the time when reprogrammed transcripts start to be detected (Halley-Stott et al. 2010).

\section{Nuclear actin polymerization is required for transcriptional reactivation of Oct4}

We examined whether polymerized nuclear actin is important for transcriptional reactivation by several different methods (Supplemental Fig. S4A). To inhibit nuclear actin, a monoclonal antibody against $\beta$-actin (clone AC15) that recognizes the $\mathrm{N}$-terminal region of $\beta$-actin was injected into the GV with donor $\mathrm{C} 2 \mathrm{C} 12$ nuclei. Forty-eight hours after NT, Oct4 reactivation was significantly inhibited $(P=0.0029$; fivefold down $)$ by AC15 injection (Fig. 2A). This antibody specifically and robustly recognizes nuclear $\beta$-actin in GVs and shows

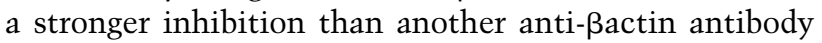
(clone AC40) (data not shown). To check the effect of antibody injection on actin polymerization, nuclear F-actin in the antibody-injected oocytes was visualized by GFPUtrCH probes. As expected, less F-actin was found in the NT oocytes coinjected with AC15 (Supplemental Fig. S4B).

Several actin mutants that do not polymerize (G13R and R62D) or that enhance polymerization (G15S and
S14C) have been reported (Posern et al. 2002, 2004). We expressed these actin mutants in oocytes by mRNA injection, and somatic nuclei were subsequently injected (Supplemental Fig. S4A [panel ii],C). The mutant that enhances polymerization, G15S, significantly enhanced $(P=0.025)$ Oct4 reactivation by sixfold (Fig. 2B, black bar). The stronger effect of G15S on Oct4 reactivation compared with S14C may be explained by the fact that G15S has a higher affinity to bind actin-associated nucleotides than S14C (Posern et al. 2004). In contrast, actin mutants unable to polymerize did not increase Oct4 reactivation, but $\mathrm{R} 62 \mathrm{D}$ rather reduced the reactivation by more than twofold (Fig. 2B, gray bar). The difference between R62D and G15S in Oct4 reactivation was 14-fold. These results indicate that actin polymerization is important for Oct4 gene reactivation.

We next inhibited actin polymerization by the actindepolymerizing drug cytochalasin $\mathrm{B}(\mathrm{CB})$ during incubation of NT oocytes (Supplemental Fig. S4A, panel iii). Treatment with CB greatly reduced polymerized actin in GVs (Supplemental Fig. S4D), although a faint signal of GFP-UtrCH could still be detected if detection gain was increased. CB treatment also reduced Oct4 reactivation (down to $50 \% 48 \mathrm{~h}$ after NT) (Fig. 2C).

Actin is known as an inhibitor of DNaseI. Therefore, it is possible that transplanted nuclei are somewhat degraded by endogenous DnaseI, and changing actin polymerization could affect this DNaseI activity. As a result, increased Oct 4 transcription would be detected after increasing actin polymerization and vice versa. We tested this possibility by examining the integrity of the DNA of injected nuclei using the same quantitative PCR (qPCR) primers as for the transcription assay (Supplemental Fig. S5). During the culture of NT oocytes, no significant DNA degradation was observed (Supplemental Fig. S5A). Furthermore, changing the amount of polymerized actin in the GV (discussed in the next section) did not influence DNA degradation, at least on the region examined for the transcriptional reprogramming assay (Supplemental Fig. S5B). These results indicate that altered Oct4 expression after changing nuclear actin polymerization is not attributable to altered DNaseI activity in degrading injected DNA.

Even though evidence that nuclear actin is important for Oct4 reactivation has been obtained, we still could not exclude the involvement of cytoplasmic actin-mediated pathways in gene reactivation. Isolated Xenopus GVs can be cultured in mineral oil without losing transcriptional reprogramming activity (Jullien et al. 2010), so that reprogramming is achieved entirely by oocyte GV components. After isolation of GVs, nuclei were injected with $\mathrm{CB}$ or DMSO, a vehicle of CB (Supplemental Fig. S4A, panel iv). We injected $50 \mu \mathrm{g} / \mathrm{mL}$ CB per $10 \mathrm{~nL}$ into the GVs, which depolymerized almost all actin in GVs (Bohnsack et al. 2006). After a 48-h incubation, Oct4 reactivation was detected in control samples (Fig. 2D, $\mathrm{CB}^{-}$), but a threefold reduction was seen when $\mathrm{CB}$ was included (Fig. 2D). CB binds to the barbed end of polymerized actin, inhibits further polymerization, and results in an increased proportion of monomeric actin (G-actin). If $\mathrm{G}$-actin binds to 
A

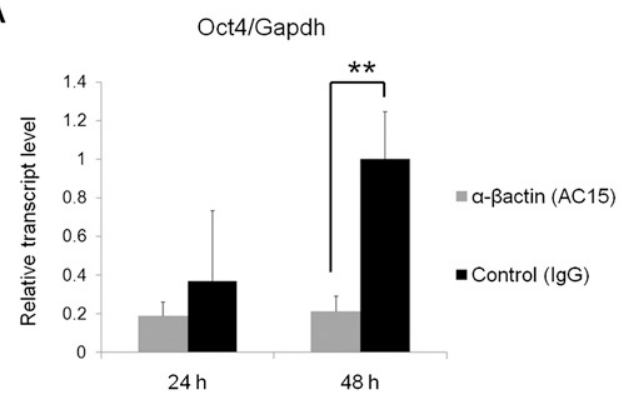

C

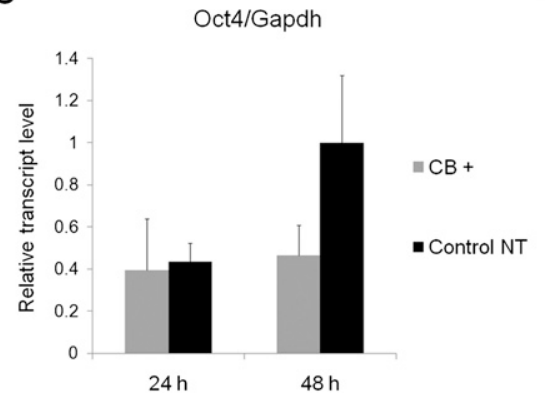

B

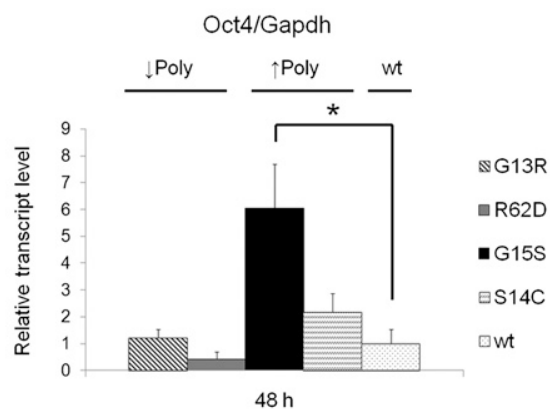

E

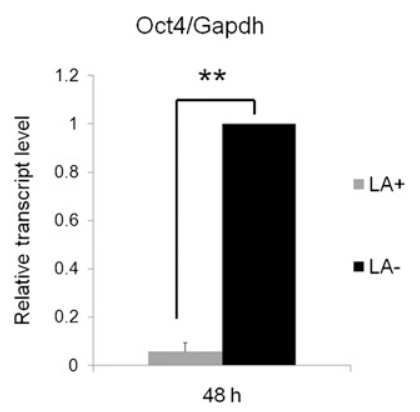

Figure 2. Nuclear actin polymerization is necessary for transcriptional reprogramming of Oct4. (A) Anti- $\beta$ actin antibody injection (clone AC15) into GVs inhibits the transcriptional reactivation of Oct4 in NT oocytes. IgG was injected as a control. Relative fold increases of gene transcripts to control NT were measured by qPCR. Transcription was analyzed $24 \mathrm{~h}$ and $48 \mathrm{~h}$ after NT. Data represent mean $\pm \mathrm{SEM}_{;}\left({ }^{\star \star}\right) P=0.0029 ; \mathrm{F}$ and T-test against control, antibody injection: $n=8$ at $48 \mathrm{~h}$ and $n=5$ at $24 \mathrm{~h}$; control injection: $n=4$ at $48 \mathrm{~h}$ and $n=2$ at $24 \mathrm{~h}$. (B) Actin mutant expression influences transcriptional reactivation of Oct4 in NT oocytes. Several human actin mutants (G13R, R62D, G15S, and S14C) and human wild-type actin (wt) were expressed in oocytes, and these oocytes were used for NT. Transcript level is relative to control wild type. Data represent mean $\pm \mathrm{SEM}_{;}\left({ }^{\star}\right) P=0.025 ; \mathrm{F}$ and $T$-test against wild type, $n=6$. $(C)$ The effect of actin-depolymerizing reagent on Oct 4 reactivation in NT oocytes. CB was added to culture medium at a concentration of $5 \mu \mathrm{g} /$ $\mathrm{mL}$ during $48 \mathrm{~h}$ of culture. Data represent mean $\pm \mathrm{SEM} \mathrm{CB}^{+}: n=10$ at $48 \mathrm{~h}$ and $n=4$ at $24 \mathrm{~h}$; control: $n=11$ at $48 \mathrm{~h}$ and $n=4$ at $24 \mathrm{~h}$. $(D)$ Oct4 reactivation from transplanted nuclei is inhibited by depolymerizing nuclear actin with CB in oil GVs. Nuclei suspended in CBcontaining solution (gray bar, $\mathrm{CB}^{+}$) or DMSO-containing solution (black bar, $\mathrm{CB}^{-}$) were injected into oil GVs, and transcriptional activation was examined by qRT-PCR analysis. Transcript level is relative to control $\mathrm{CB}^{-}$. Data represent mean $\pm \mathrm{SEM} ; n=6$. $(E)$ Oct4 reactivation from transplanted nuclei is inhibited by depolymerizing nuclear actin with LA in oil GVs. Nuclei suspended in LAcontaining solution (gray bar, $\mathrm{LA}^{+}$) or DMSO-containing solution (black bar, $\mathrm{LA}^{-}$) were injected into oil GVs. Data represent mean \pm $\mathrm{SEM}_{;}\left(^{\star \star}\right) P=0.0016 ; \mathrm{F}$ and $T$-test against $\mathrm{LA}^{-} ; n=3$.

an activator of Oct4 and sequesters it like the transcriptional coactivator MAL (Vartiainen et al. 2007), increased G-actin would cause down-regulation of Oct4. To exclude this possibility, we repeated the oil GV experiment with another actin-depolymerizing reagent, latrunculin A (LA), which binds to G-actin and inhibits polymerization. This again led to a striking inhibition of transcriptional reactivation of Oct4 by 17 -fold $(P=0.0016)$ (Fig. 2E). In conclusion, nuclear actin polymerization is necessary for the reactivation of the silenced Oct4 gene in oocytes.

An actin signaling protein, Toca-1, regulates Oct4 reactivation

We showed here a requirement of actin polymerization for strong Oct 4 reactivation by modulating nuclear actin polymerization. However, one possibility is that Oct4 reactivation is inhibited by secondary nonspecific effects, because antibody injection and chemical treatment may have a range of pleiotropic effects. To exclude this possibility, it is important to find a specific upstream molecule that regulates nuclear actin polymerization and Oct4 reactivation. The dynamics of actin polymerization are regulated by actin nucleators and actin signaling proteins. These factors are localized mainly in the cytoplasm, but some reports suggest that several actin nucleators are present in nuclei, although little is known about their function (Percipalle 2009). We tested four such factorsToca-1 (Ho et al. 2004), N-WASP (Wu et al. 2006), Rac1 (Eden et al. 2002), and JMY (Zuchero et al. 2009)-to ask whether they play a role in a reprogramming context. These factors were overexpressed as HA-tagged proteins in oocytes by mRNA injection before NT (Fig. 3A). They were all expressed in GVs, although only a low level of JMY was detected (Fig. 3B). As a control, different amounts of these proteins were expressed by injecting various amounts of mRNA (1.5, 4.6, or $13.8 \mathrm{ng})$. All factors, except for N-WASP, enhanced Oct4 reactivation in transplanted $\mathrm{C} 2 \mathrm{C} 12$ nuclei by up to fourfold, but only Toca-1 injection with 4.6 and 13.8 ng of mRNA showed a statistically significant and dose-dependent positive effect ( $P=0.024$ and 0.014 , respectively) on Oct4 transcriptional 
Miyamoto et al.

A
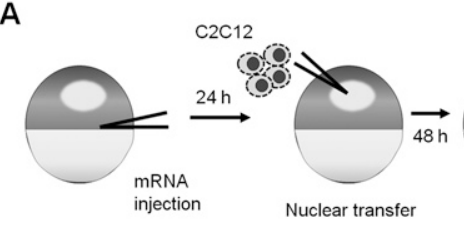

C

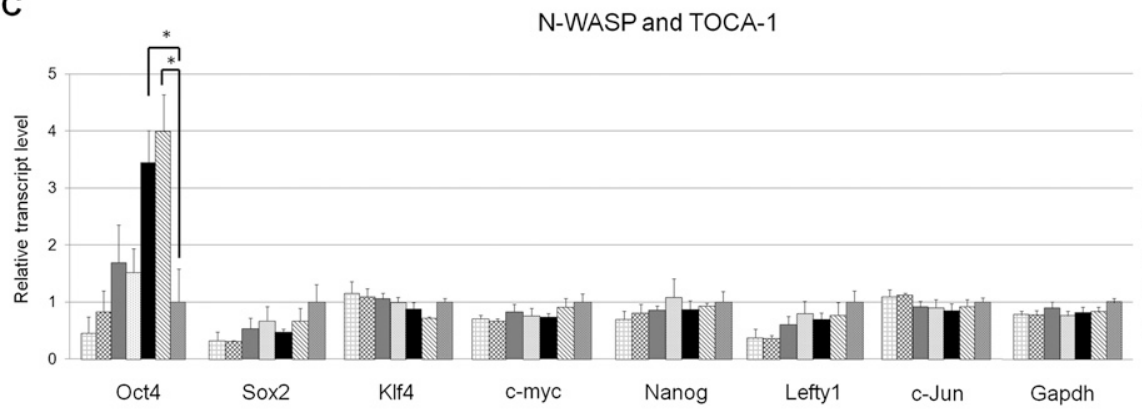

B

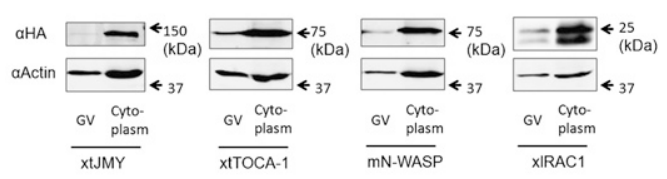

RAC1 and JMY

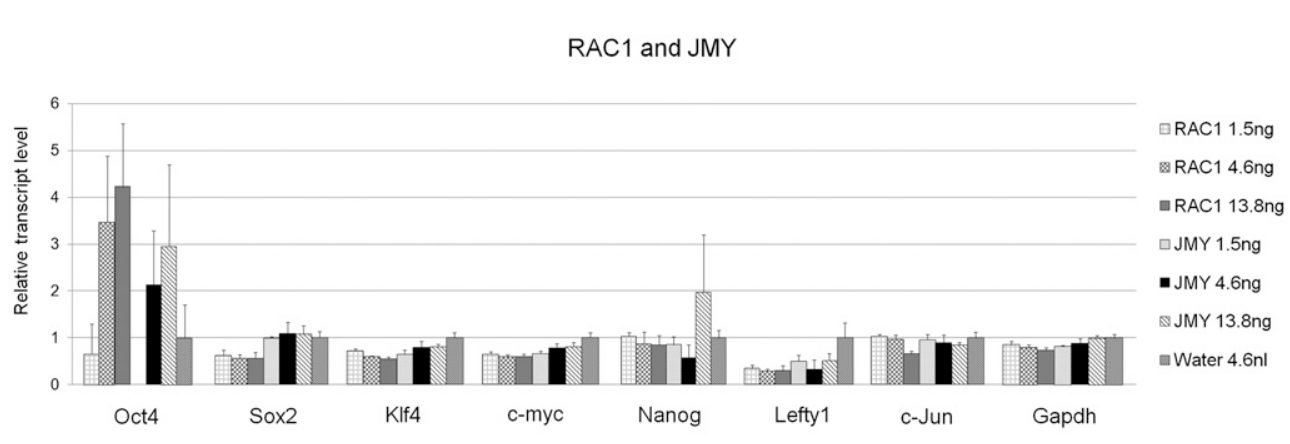

D

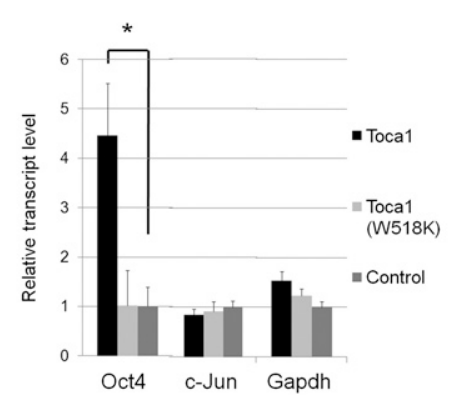

C-Jun Gapd
N-WASP $1.5 \mathrm{ng}$

N-WASP $4.6 \mathrm{ng}$

- N-WASP 13.8ng

TOCA-1 $1.5 \mathrm{ng}$

- TOCA-1 4,6ng

\& TOCA-1 13.8ng

$=$ Water $4.6 \mathrm{nl}$
E

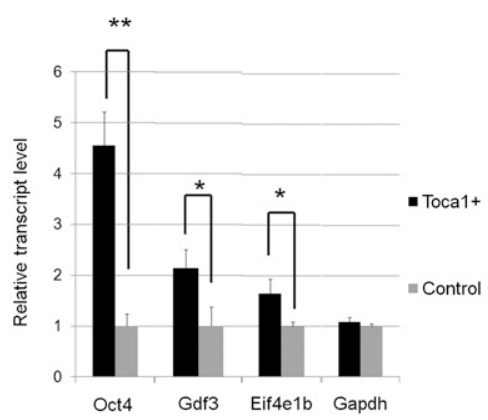

Figure 3. An actin signaling protein, Toca-1, enhances Oct4 reactivation. $(A)$ Schematic diagram of the experimental strategy to assess the effect of actin nucleators and actin signaling proteins on transcriptional reprogramming from transplanted C2C12 nuclei. $(B)$ Four factors tagged with HA are expressed as proteins in both the GV and cytoplasm. These include Xenopus tropicalis JMY (xtJMY), X. tropicalis TOCA-1 (xtTOCA-1), mouse N-WASP (mN-WASP), and X. laevis RAC1 (xlRAC1). The proteins were detected by Western blot analysis using anti-HA antibody $24 \mathrm{~h}$ after mRNA injection. Actin was used as a loading control. $(C)$ The effect of overexpression of the actin polymerization regulator on transcriptional reprogramming. Relative fold increases of gene transcripts to control waterinjected samples are shown, measured by qPCR. Data represent mean $\pm \mathrm{SEM}_{;}\left({ }^{\star}\right) P<0.05 ; \mathrm{F}$ and $T$-test against the control water injection; $n=4$. (D) A mutant form of Toca-1, Toca-1(W518K), does not enhance Oct4 reactivation, while wild-type Toca-1 enhances it. Toca-1(W518K) was similarly overexpressed in oocytes by mRNA injection. Relative fold increases of gene transcripts to control waterinjected samples are shown, measured by qPCR. Data represent mean $\pm \mathrm{SEM}_{;}\left(^{\star}\right) P=0.018 ; \mathrm{F}$ and $T$-test against the control; Tocal: $n=3$; others: $n=4)$. (E) Reactivation of Oct4, Gdf3, and Eif4e1b genes was enhanced by the overexpression of TOCA-1. Gdf3 is a pluripotency gene and Eif $4 e 1 b$ is an oocyte-specific gene. Data represent mean $\pm \mathrm{SEM}_{;}\left(^{\star \star}\right) P<0.02 ;\left(^{\star}\right) P<0.05$; F and T-test against the control; $n=5-6)$.

reactivation (Fig. 3C). Other pluripotency-related genes (Sox2, Klf4, c-myc, Nanog, and Lefty1) and genes highly expressed in donor cells (c-Jun and Gapdh) were not influenced by TOCA-1 overexpression (Fig. 3C), suggesting a specific effect of TOCA-1 on Oct4. Remarkably, this positive effect of TOCA-1 on Oct4 reactivation was 
abrogated by overexpressing the point mutation of TOCA$1(\mathrm{~W} 518 \mathrm{~K})$, which is unable to promote actin polymerization (Fig. 3D; Ho et al. 2004).

Since TOCA-1 has a selective effect on Oct4 reactivation, we investigated other genes whose reactivation is enhanced by TOCA-1 overexpression in the same way as Oct4. We checked a list of pluripotency genes that change epigenetic modifications in the same way as Oct4 during reprogramming (Mikkelsen et al. 2008). In addition, oocyte-specific genes are known to be reactivated in our system (Tamada et al. 2006). Thus, Gdf3 and Eif4e1b were selected as a pluripotent gene and an oocyte-specific gene, respectively. The effect of TOCA-1 overexpression on the reactivation of these genes was examined. Gdf3 and Eif4e1b were expressed very little in C2C12 cells, but were reactivated after NT to Xenopus GVs /data not shown). The transcription of these genes and Oct4 was significantly enhanced by TOCA-1 (Fig. 3E). The positive effect of Toca-1 is not limited to Oct4.

We next examined whether TOCA-1 localizes to transplanted C2C12 nuclei. Nuclei were transplanted into Toca1-Cherry and GFP-UtrCH mRNA-injected oocytes and observed by the oil GV procedure. TOCA1-CHERRY was detected in GVs and injected nuclei (Fig. 4A, white arrow). TOCA-1 was present in the GV and was preferentially localized in the area where F-actin is abundantly detected. Some nuclei in which Tocal-Cherry was not present did not show filamentous actin (Fig. 4A, blue arrow). To confirm that endogenous TOCA-1 is present in the GV, a Western blot was performed. TOCA-1 was present in the Xenopus oocyte cytoplasm and also at a weaker level in the GV, which is 20 times smaller in

A
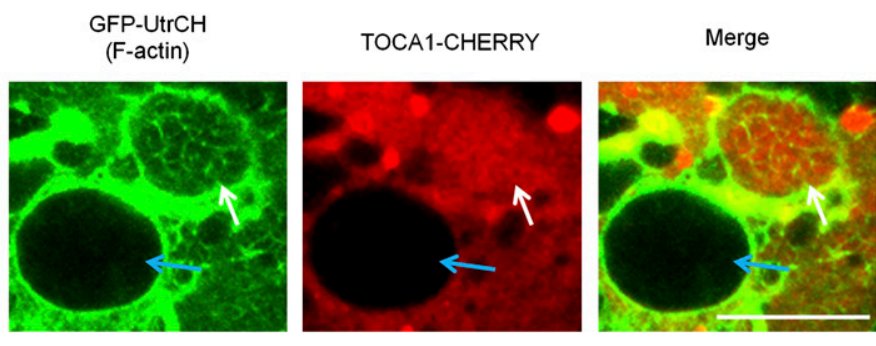

B

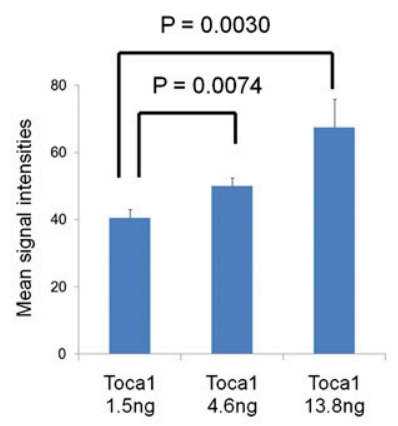

C a-ßactin
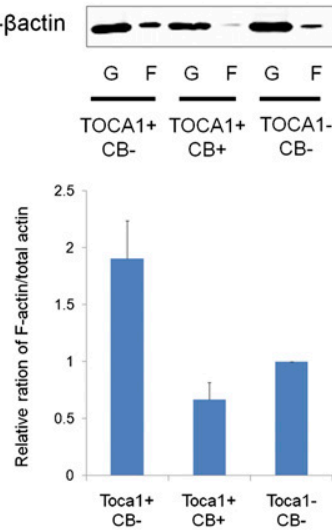

D
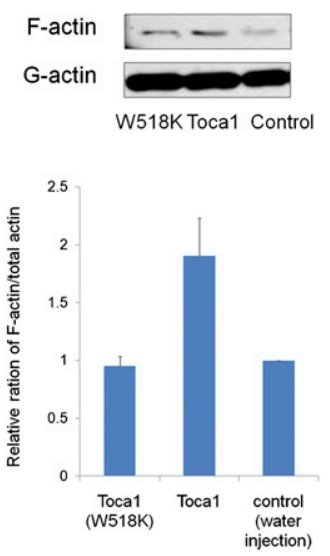

Figure 4. Toca-1 exists in a transplanted nucleus and enhances nuclear actin polymerization. (A) TOCA1-CHERRY is present in injected nuclei. Tocal-Cherry and GFP-UtrCH mRNA were injected before NT. The injected nuclei were observed $48 \mathrm{~h}$ after NT by confocal microscopy using the oil GV method. A nucleus in which TOCA1-CHERRY is present shows nuclear F-actin formation (white arrow). In contrast, nuclear F-actin is not detected in a nucleus without TOCA1-CHERRY (blue arrow). Bar, $20 \mu \mathrm{m}$. (B) TOCA1 overexpression increases nuclear F-actin formation. Different amounts of TOCA1 were expressed in oocytes by mRNA injection with different concentrations. These injected oocytes were used for NT. The oocytes were subjected to immunofluorescence analysis and phalloidin staining $48 \mathrm{~h}$ after NT. Images were obtained from randomly selected areas. Nuclear F-actin amounts were quantified using the ImageJ software (Materials and Methods). Statistical differences were measured by F and T-tests. Data represent mean \pm SEM; Toca-1 $1.5 \mathrm{ng}: n=45$; Toca-1 $4.6 \mathrm{ng}$ and $13.8 \mathrm{ng}: n=55 .(C)$ Actin fractionation experiment indicates that TOCA-1 overexpression increases the F-actin population in GVs. TOCA-1 was expressed in oocytes by mRNA injection. GVs were collected from these injected oocytes or noninjected oocytes, and total actin was fractionated to monomeric and polymeric actin (G- and F-actin, respectively). The amounts of G- and F-actin were measured by Western blot analysis using anti- $\beta$ actin antibody. CB was added to culture medium at a $1 \mu \mathrm{g} / \mathrm{mL}$ concentration to check that enhanced actin polymerization was diminished with this concentration. F-actin proportion in total actin was compared among three samples, and fold differences relative to the control noninjected oocytes (Toca ${ }^{-}$and $\mathrm{CB}^{-}$) are shown. Data represent mean \pm SEM; $n=2$. $(D)$ Actin fractionation experiment indicates that overexpression of a TOCA-1 mutant, W518K, does not increase the F-actin population in GVs. F-actin ratio in total actin is relative to control water-injected oocytes. Data represent mean \pm SEM; $n=2$. 
volume than the cytoplasm (Supplemental Fig. S6A). Immunoprecipitation of TOCA-1 from Xenopus GV extracts confirmed that TOCA-1 is also in the GV, although it is not abundant (Supplemental Fig. S6B). Immunofluorescence analysis was carried out in order to see localization of endogenous TOCA-1 in transplanted nuclei. Endogenous TOCA-1 was present throughout the GV, including in transplanted nuclei (Supplemental Fig. S6C).

We finally examined the effect of TOCA-1 overexpression on actin polymerization using phalloidin staining and image analysis (Materials and Methods). Injection of $4.6 \mathrm{ng}$ and $13.8 \mathrm{ng}$ of Toca-1 mRNA significantly increased nuclear F-actin formation compared with 1.5-ng injection (Fig. 4B), correlating well with Oct4 reactivation data (Fig. 3C). An actin fractionation experiment also showed that the proportion of nuclear F-actin increased after TOCA-1 overexpression (Fig. 4C), and, as expected, the mutant form of TOCA-1(W518K) did not increase the relative proportion of F-actin (Fig. 4D). Our results demonstrate that TOCA-1 enhances nuclear actin polymerization and Oct4 transcriptional reactivation.

\section{Nuclear actin is important for both continuing transcription and the transcriptional reprogramming of Oct4}

Here we showed a requirement of nuclear actin polymerization for Oct4 reactivation and of an upstream molecule, Toca-1, for this event. We next asked whether nuclear actin is involved in ongoing transcription of Oct4 as well as in its reprogramming processes. Two experiments were designed to test this. First, as depicted in Supplemental Figure S4A (panel i), the anti- $\beta$ actin antibody was injected into a GV with ES nuclei in which Oct4 was already continuously expressed. Oct4 transcription from transplanted ES nuclei was significantly inhibited $(P=0.0076)$ by the antibody injection (Fig. 5A). Since transcriptional reprogramming is not required for continuous Oct4 expression from transplanted ES nuclei, nuclear actin is involved in the ongoing transcription of Oct4. Second, we asked whether TOCA-1 overexpression enhances continuous Oct4 expression in transplanted ES nuclei. Although TOCA-1 reproducibly enhanced Oct4 reactivation in transplanted $\mathrm{C} 2 \mathrm{C} 12$ nuclei using the same batch of oocytes, the continuous Oct4 transcription from transplanted ES nuclei was not affected by TOCA-1 (Fig. $5 \mathrm{~B})$. This result indicates that TOCA-1-mediated actin polymerization accelerates a reprogramming process, but does not affect ongoing transcription. We conclude that nuclear actin, but not Toca-1, is involved in both ongoing transcription and reprogramming.

\section{Nuclear actin polymerization and chromatin remodeling}

Increased nuclear actin polymerization enhances Oct4 reactivation. We asked whether nuclear actin polymerization could affect the chromatin states of transplanted nuclei. We carried out coimmunoprecipitation analysis to ask whether oocyte nuclear actin was bound to chromatin proteins related to transcription and reprogramming (Zhao et al. 1998; Bettinger et al. 2004; Hofmann et al. 2004; Dion et al. 2010). This revealed that nuclear actin was bound to RNA polymerase II (Pol II) and the BAF complex (Fig. 6A). Immunofluorescence analysis also showed colocalization of nuclear actin and elongating Pol II (data not shown). These results suggest that actin in the GV may play a role in not only transcription, but also chromatin remodeling.

We sought to perform quantitative chromatin immunoprecipitation (qChIP) analysis in order to see an effect of nuclear actin polymerization on chromatin. However, ChIP using NT oocytes is technically challenging because it requires numerous transplanted nuclei. To detect the binding of nonhistone chromatin proteins like remodeling complexes, we used a transgenic ES cell line that possesses $\sim 30$ copies of the Oct4 regulatory region driving
A

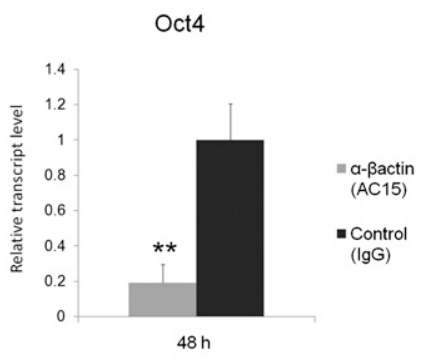

B

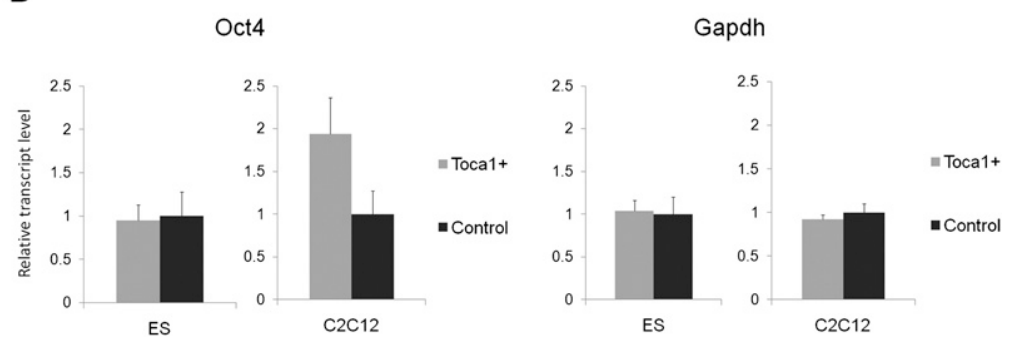

Figure 5. Nuclear actin polymerization is important for both ongoing transcription and transcriptional reprogramming of Oct4. (A) Anti-ßactin antibody injection into GVs inhibits Oct4 transcription from transplanted ES nuclei. IgG was injected as a control. Relative fold increases of gene transcripts to control NT were measured by qPCR. Transcription was analyzed $48 \mathrm{~h}$ after NT. Data represent mean $\pm \mathrm{SEM}\left(^{\star \star}\right) P=0.0076 ; \mathrm{F}$ and $T$-test against the control; $n=5$. (B) TOCA-1 overexpression does not enhance Oct4 transcription from transplanted ES nuclei, while it enhances Oct4 transcription from C2C12 nuclei. Transcript level is relative to control water-injected samples. Data represent mean \pm SEM; ES nuclei: $n=4$; C2C12 nuclei: $n=3$. 
A

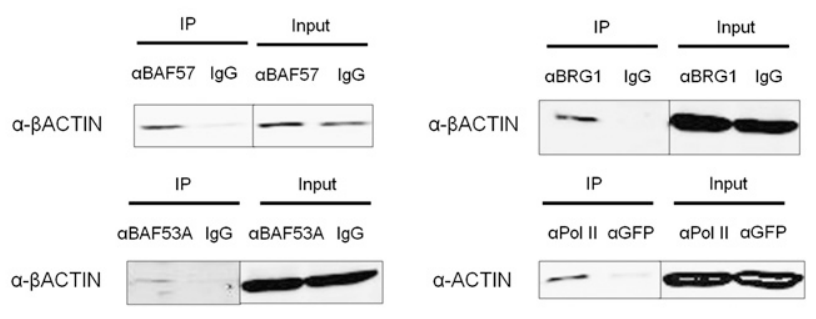

B

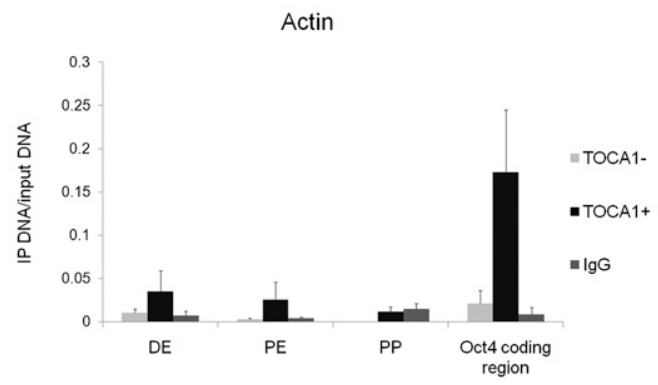

Figure 6. Association of nuclear actin with chromatin proteins and chromatin of transplanted nuclei. (A) Coimmunoprecipitation analysis in GV lysates to examine binding of nuclear actin to Pol II and the BAF complex. GV proteins were immunoprecipitated by IgG and antibodies against BAF57, BRG1, BAF53A, and Pol II, and were analyzed by Western blots by probing for $\beta$-actin and actin. Five percent input was loaded. $(B)$ TOCA-1 overexpression enhances nuclear $\beta$-actin binding to the Oct4 gene. ChIP analysis using anti- $\beta$ actin antibody was performed with TOCA-1-overexpressed NT oocytes $\left(\mathrm{Tocal}^{+}\right)$and normal NT oocytes $\left(\right.$ Toca $\left.1^{-}\right) 48 \mathrm{~h}$ after NT using RA-ES cells. The Oct4 gene regulatory region was expressed as distal enhancer (DE), proximal enhancer $(\mathrm{PE})$, and proximal promoter $(\mathrm{PP})$. As a control, ChIP analysis using nonspecific IgG was carried out with normal NT oocytes. The relative abundance of precipitated DNA against total input DNA was measured by qPCR. Data represent mean $\pm \mathrm{SEM} ; n=5$.

Neomycin resistance gene (Neo) expression (Supplemental Fig. S7A). After retinoic acid differentiation, the retinoic acid-treated ES cells (RA-ES cells) showed strong down-regulation of $\mathrm{NeO}$, indicating a silencing of the transgenic Oct4 promoter (Supplemental Fig. S7B). Silenced $\mathrm{NeO}$ expression in RA-ES cells was reactivated after NT, and reactivation was enhanced by TOCA-1 overexpression (Supplemental Fig. S7C). Furthermore, the enhanced Neo expression was inhibited by adding 1 $\mu \mathrm{g} / \mathrm{mL}$ CB during incubation of NT oocytes (Supplemental Fig. S7C), and this concentration of $\mathrm{CB}$ abolished increased actin polymerization by TOCA1 (Fig. 4C). These results indicate that the transgenic Oct4 promoter behaves like the endogenous Oct4 promoter.

The binding of nuclear actin to the Oct4 upstream region was examined by qChIP analysis. AC15 antibody was used because our preliminary data suggested its precipitation ability was stronger than another anti- $\beta$ actin antibody (A2103, Sigma) that also recognizes the $\mathrm{N}$-terminal region, and because it has been used for ChIP analysis
(Ambrosino et al. 2010; Xu et al. 2010). Nuclear actin binding to the Oct4 regulatory region and gene body was observed, and TOCA-1 overexpression enhanced its binding by up to 10 -fold (Fig. 6B). The gene body examined here is located close to the polyadenylation site of the Oct4 gene. These results suggest that TOCA-1 enhances the binding of nuclear actin to Oct4. We also examined Pol II and BAF complex binding after TOCA-1 overexpression. Pol II binding to the Oct4 gene was slightly increased by TOCA-1 overexpression (Supplemental Fig. S8A), implying that TOCA-1 weakly affects Pol II localization in our system. For ChIP analysis of the BAF complex, BAF57 antibody was used because it is highly conserved in the complex among many species (Ho and Crabtree 2010). TOCA-1 overexpression induced an approximately twofold greater BAF57 binding in the Oct4 regulatory region (Supplemental Fig. S8B). Together, the effect of TOCA-1 overexpression on chromatin binding appeared strongly in nuclear actin, modestly in the BAF complex, and weakly in Pol II. In conclusion, TOCA-1 overexpression, accompanied by enhanced nuclear actin polymerization, entails rearrangement of chromatinbinding proteins. These results do not explain all of the positive effects of TOCA-1 overexpression on Oct4 reactivation, but the enhanced access of chromatin factors by TOCA-1 might be one explanation for this positive effect.

\section{Discussion}

Nuclear actin was found $>30$ years ago. Early studies also showed its involvement in the expression of proteincoding genes (Scheer et al. 1984). However, the significance of these findings has been questioned for a long time. One of the major reasons for this skepticism is that the actin filaments normally observed in the cytoplasm could not be visualized in the nucleus. Nevertheless, recent studies provided convincing evidence for nuclear actin (McDonald et al. 2006) and its role in nuclear processes (Visa and Percipalle 2010). One elegant contribution showed that a nuclear actin mesh is formed in the giant Xenopus oocyte nucleus (Bohnsack et al. 2006). This nuclear F-actin scaffold is required to support mechanical integrity of the giant nucleus. We extended this view using live-cell imaging. The F-actin in transplanted nuclei undergoes a global change during reprogramming, and the timing of nuclear actin formation is positively correlated with transcriptional reprogramming.

Nuclear actin is involved in transcription by all three RNA polymerases (Hofmann et al. 2004; Hu et al. 2004; Philimonenko et al. 2004), and in transcriptional initiation after cytokine stimulation (Hofmann et al. 2004) and retinoic acid treatment (Ferrai et al. 2009). Although there is evidence for actin's involvement in transcription, in vivo evidence is still lacking. In addition, these results are accompanied by concerns about contamination and involvement of cytoplasmic actin. Considering that both cytoplasmic and nuclear actin synergistically play an important role in serum response factor-induced transcription (Vartiainen et al. 2007), an experimental system that can rule out cytoplasmic actin is useful. The Xenopus giant 
GV enables us to isolate it in a nonaqueous medium without losing its transcriptional activity (Lund and Paine 1990; Jullien et al. 2010). Since reprogramming in an oil GV relies on nuclear contents, the substantial inhibition of gene reactivation by depolymerizing GV actin in this system supports our conclusion.

Cytoplasmic actin filament formation and its proper function are dependent on actin nucleators /Campellone and Welch 2010). N-WASP, an actin nucleator, is present in nuclei and makes a bridge between actin and Pol II (Wu et al. 2006), but its function is largely autoinhibited. Therefore, overexpression of $N$-WASP itself might not have any effects on gene reactivation. Toca-1 is identified as an upstream regulator of N-WASP to release this inhibition (Ho et al. 2004), and faithfully enhances Oct4 reactivation in our experiments. The prominent effect of Toca-1 on gene reactivation may be explained by its characteristic as an upstream molecule in actin polymerization signaling (Ho et al. 2004; Fricke et al. 2009). The second strongest effect was induced by Rac1. Considering that Rac1 and Toca-1 share the same downstream target $(N-W A S P$ and $S C A R / W A V E)$, these actin signaling pathways may include an important step for Oct4 reactivation.

Nuclear actin and the BAF complex were facilitated in their binding to Oct4 by Toca-1. This is possibly because Toca1-mediated actin polymerization near the Oct4 gene increased an opportunity for the BAF complex to be bound at the area, resulting in an increased chance for BAF to associate with chromatin. This model agrees with a previous study showing that an actin signaling protein, PIP2, allows the BAF complex to associate with polymerized actin and chromatin (Zhao et al. 1998; Rando et al. 2002). The BAF complex opens chromatin by nucleosome sliding or ejection (Cairns 2009). Importantly, BAF knockdown induces down-regulation of Oct4 (Ho et al. 2009; Kidder et al. 2009). This positive regulator presumably converts chromatin into an accessible state for transcriptional activators (Singhal et al. 2010), which may allow general transcription factors to act on Oct4 transcription. Indeed, Pol II enhanced its association with the Oct4 gene in parallel with these events in our experiment. Toca-1induced actin polymerization might act upstream in this series of reprogramming events.

Our experiments and previous reports show that nuclear actin is associated with regulatory regions of activating genes and is involved in selective gene activation (Ferrai et al. 2009; Taylor et al. 2010; Xu et al. 2010). Although the reason why only a subset of gene reactivations was affected by actin polymerization is still not clear, one model for how actin selectively binds to specific genomic sites can be proposed. WASP is supposed to be recruited to DNA by interaction with the transcription factor SP1 (Taylor et al. 2010). Such a recruited actin nucleator can induce actin nucleation at this site, and thus nuclear actin localization occurs at a specific region. Interestingly, the SP1 site on the Oct4 promoter is necessary for DNA demethylation and transcription (Simonsson and Gurdon 2004). Recruitment of N-WASP and nuclear actin on the SP1 site might be a necessary step for Oct4 transcriptional reprogramming.
We assume that nuclear actin-mediated reprogramming is a comparatively late step in the whole transcriptional reprogramming process in oocytes. The beginning of reprogramming is characterized by a prompt incorporation of the embryonic linker histone B4 and loss of somatic linker histone H1 (Jullien et al. 2010). Subsequently, gradual swelling of transplanted nuclei proceeds and transcription starts $\sim 24 \mathrm{~h}$ after NT. Notably, nuclear actin starts to appear at approximately the same time as transcription starts. As transcription increases toward a peak level after further culture, an active histone mark (histone H3K4 methylation) is added (Murata et al. 2010) and more actin is detected in transplanted nuclei. Together with these observations and our present results, nuclear actin is likely to be implicated in the beginning of the transcriptional initiation process and enhancement of transcription. This fits with our results because nuclear actin is associated with the BAF complex and Pol II; these have crucial roles in transcriptional initiation and enhancement. This model is further supported by a recent study showing that an actin nucleator binds to $\mathrm{H} 3 \mathrm{~K} 4$ trimethyltransferase RBBP5 and is important for its activity for activating genes (Taylor et al. 2010).

The role of nuclear actin has been elusive. Nevertheless, many attempts have revealed its novel function in the nucleus, including transcription and physical gene movement. Here we add a new function of nuclear actin in transcriptional reprogramming. Moreover, our results emphasize the significant contribution of nuclear actin polymerization in transcriptional activation. The importance of G-actin in transcriptional regulation has been shown clearly in a previous report (Vartiainen et al. 2007). We therefore propose that both nuclear G- and F-actin are involved in transcriptional regulation in different ways, and the balance between those two forms of actin may be important for regulating transcription. Massive amounts of nuclear actin, which actively change its polymerized states during reprogramming, are stored in the oocyte nucleus. This helps to explain why an oocyte can reprogram multiple nuclei efficiently and rapidly.

\section{Materials and methods}

\section{NT and mRNA injection}

Xenopus oocytes were defolliculated with Liberase (05401127001, Roche). Defolliculated oocytes were kept in modified Barth's solution (MBS) at $14^{\circ} \mathrm{C}$ before use. Mouse cells (ES, RA-ES, and C2C12 cells) were permeabilized with $100 \mu \mathrm{g} / \mathrm{mL}$ Streptolysin O (SLO) for $5-15 \mathrm{~min}$ at $37^{\circ} \mathrm{C}$. Successful permeabilization (>95\%) was confirmed by Trypan blue staining. Permeabilization was stopped by the addition of modified Merriam's medium $(20 \mathrm{mM}$ HEPES at $\mathrm{pH} 7.5,75 \mathrm{mM} \mathrm{KCl}, 2 \mathrm{mM} \mathrm{MgCl}_{2}, 2 \%$ PVP, $2 \mathrm{mM}$ $\beta$-mercaptoethanol) containing BSA. These permeabilized cells were suspended in modified Merriam's medium with $1 \%$ BSA to achieve a concentration of 250-300 nuclei per $10 \mathrm{~nL}$, and $10 \mathrm{~nL}$ of the cell suspension was injected into a Xenopus oocyte nucleus $(\mathrm{GV})$. In every experiment, calibration of the injected cell number was performed to deliver a constant number of nuclei to each oocyte. Successful injection was confirmed by dissecting the injected oocytes, since injected nuclei can be observed under 
a microscope. The injected oocytes were cultured for up to $3 \mathrm{~d}$ at $16^{\circ} \mathrm{C}$ in MBS supplemented with $0.1 \%$ BSA and antibiotics.

Different volumes of mRNA, depending on an experiment, were injected into oocytes equatorially. The mRNA injection was performed $1 \mathrm{~d}$ before NT in order to accumulate the overexpressed proteins in oocytes. Amounts of injected mRNA were as follows: GFP-UtrCH, $40.8 \mathrm{ng}$ per $40.8 \mathrm{~nL} ; \beta$-actin-R62D/S14C/ G15S/G13R/wt-HA, $27.6 \mathrm{ng}$ per $27.6 \mathrm{~nL}$; xtJMY-HA, xtTocalHA, myc-hToca1(W518K), xtToca-1-Cherry-HA, mN-WASP-HA, and xlRac1-HA, $13.8 \mathrm{ng}$ per $13.8 \mathrm{~nL}$; RFP-histone B4 and Cherryhistone $\mathrm{H} 2 \mathrm{~B}, 4.6 \mathrm{ng}$ per $4.6 \mathrm{~nL}$ or $1.5 \mathrm{ng}$ per $4.6 \mathrm{~nL}$.

\section{Oil GV method}

NT oocytes cultured in MBS were transferred onto a slide glass and the MBS solution was removed as much as possible. The oocytes were moved into mineral oil and GVs were dissected (oil GVs). The dissected GVs were transferred onto a slide glass for confocal microscope analysis. For the NT experiment into oil GV, permeabilized cells (250-300 nuclei per $4.6 \mathrm{~nL})$ were injected into the dissected GV. Modified Merriam's medium containing $50 \mu \mathrm{g} / \mathrm{mL} \mathrm{CB}$ (Sigma), $5 \mu$ M LA (Sigma), or 0.5\% DMSO was used for cell suspension. The injected GVs were cultured in mineral oil for up to $2 \mathrm{~d}$ at $16^{\circ} \mathrm{C}$.

\section{Transcriptional reprogramming assay and $q R T-P C R$}

For detecting reprogrammed transcripts from injected mouse nuclei, qRT-PCR analysis was performed (Halley-Stott et al. 2010). Four whole injected oocytes (equivalent to 1000-1200 injected nuclei) or 10 injected oil GVs were pooled as one sample, and RNA was extracted from the samples using Qiagen RNeasy columns. After RNA extraction, including on-column DNase I digestion, reverse transcription was performed using SuperScript III with gene-specific primers. Real-time PCR was performed as SYBR green assays on an ABI 7300 Real-Time PCR Cycler using standard ABI cycling condition. Primers used in this assay are listed in Supplemental Table S1. Quantification was performed using ES cell cDNA within the log-linear phase of the amplification curve. The mean quantity was normalized to mouse Gapdh transcripts (expressed as Oct4/Gapdh), or a relative transcript level of every gene was listed.

\section{Cell culture and transfection}

Mouse ES cells were grown on gelatin-coated dishes in ES medium (GMEM, 20\% ES-grade FBS [Invitrogen], MEM nonessential amino acids, sodium pyruvate, leukemia inhibitory factor [LIF] [Millipore; ESGRO], $\beta$-mercaptoethanol, antibiotics) under feeder-free condition. For retinoic acid differentiation, the ES medium was changed to the differentiation medium (GMEM, 20\% FBS [Invitrogen], MEM nonessential amino acids, sodium pyruvate, 1 $\mu \mathrm{M}$ retinoic acid, $\beta$-mercaptoethanol, antibiotics). C2C12 cells were maintained in DMEM containing $10 \%$ FBS, penicillin, and streptomycin. Transfection was performed with Lipofectamine 2000 (Invitrogen) according to the vendor's protocol. ES cells were transfected with Lac repeats-Oct4 regulatory region-Neo, and stably expressing cells were selected using G418. C2C12 cells were transiently transfected with the Cherry-laminB1 plasmid and used for NT.

\section{Live-cell imaging, immunofluorescence, image analysis}

GVs were dissected from injected oocytes in mineral oil. For F-actin staining on fixed samples, GVs were dissected one by one in GV isolation buffer $(20 \mathrm{mM}$ Tris- $\mathrm{HCl}$ at $\mathrm{pH} 7.5,0.5 \mathrm{mM}$
$\mathrm{MgSO}_{4}, 140 \mathrm{mM} \mathrm{KCl}$ ), immediately transferred into $10 \%$ paraformaldehyde containing $1 \mu \mathrm{M}$ phalloidin-TRITC (Fulka), and incubated for 20-25 min with gentle rotating. After washing with PBS containing $0.2 \%$ Tween20, DNA was stained with DAPI, followed by washing. For TOCA-1 staining, GVs were permeabilized with PBS containing $0.5 \%$ Triton $\mathrm{X}$ and blocked with PBS containing 5\% FBS and $0.2 \%$ Tween 20 . Anti-Toca-1 antibody (a gift from J. Gallop and M. Kirschner) and antiphoPolII(S2) (cloneH5:MMS-129R, Covance) were used with 1:100 dilution, and anti-rabbit IgG Alexa Fluor 488 and antimouse IgM Alexa Flour 633 were used as secondary antibodies (1:200 dilution). Confocal analysis was carried out on a Zeiss 510 META confocal LSM microscope equipped with argon (488 nm), $\mathrm{HeNe}(543$ and $637 \mathrm{~nm})$, and MaiTai $(740 \mathrm{~nm}$ ) lasers. For timelapse experiments, images were taken every $10 \mathrm{~min}$, and these were projected using Zeiss LSM 510 software.

Nuclear actin in transplanted nuclei was quantified by ImageJ software. F-actin was labeled with phalloidin-TRITC and nuclei were labeled with DAPI. By using the straight-line selection tool, a line was drawn within a transplanted nucleus whose area could be judged by DAPI staining. Strong dot-like staining was avoided when drawing the line. Mean signal intensities in the plotted areas were calculated by the Analyze tool. More than nine NT oocytes were used for the analysis, and five images of transplanted nuclei were selected randomly from each NT oocyte.

\section{$q C h I P$}

ChIP analysis was performed as described previously with modifications (Astrand et al. 2009; Jullien et al. 2010). NT oocytes that contain $\sim 300$ mouse nuclei per oocyte were transferred to MBS medium without BSA, and then a set of seven to 10 oocytes was transferred into a $1.5-\mathrm{mL}$ tube. After washing with MBS, NT oocytes were cross-linked for $10 \mathrm{~min}$ at room temperature in $1 \mathrm{~mL}$ of MBS medium containing $1 \%$ formaldehyde, with gentle shaking. Fixation was stopped by rapid washing of oocytes in MBS. The oocytes were ruptured in $280 \mu \mathrm{L}$ of homogenization buffer (50 mM HEPES at pH 7.8, $140 \mathrm{mM} \mathrm{NaCl}, 1 \mathrm{mM}$ EDTA, $1 \%$ Triton X-100, $0.1 \%$ sodium deoxycholate, $0.3 \%$ SDS, $1 \mathrm{mM}$ DTT, protease inhibitors) by pipetting and kept on ice before sonication. Sonication was carried out in $1.5-\mathrm{mL}$ tubes for $7 \mathrm{~min}$ twice with a 30 -sec on/30-sec off cycle by Bioruptor TWIN (Diagenode). Six-hundred microliters of buffer I (50 mM HEPES at $\mathrm{pH} 7.8,140 \mathrm{mM} \mathrm{NaCl}, 1 \mathrm{mM}$ EDTA, $1 \%$ Triton X-100, $0.1 \%$ sodium deoxycholate, $1 \mathrm{mM}$ DTT, protease inhibitors) was added to the sonicated samples. These solutions from two tubes were mixed in $2-\mathrm{mL}$ tubes, finally yielding $1800 \mu \mathrm{L}$. The samples were centrifuged at $13,000 \mathrm{rpm}$ at $4^{\circ} \mathrm{C}$. Supernatants were transferred, and $10 \%$ of these supernatants was taken as inputs and mixed with an equal volume of $2 \times$ Stop buffer $(40 \mathrm{mM}$ Tris$\mathrm{HCl}$ at $\mathrm{pH} 8.0,10 \mathrm{mM}$ EDTA, $1 \%$ SDS) and $0.3 \mu \mathrm{g} / \mu \mathrm{L}$ proteinase $\mathrm{K}$ (final concentration). The inputs were incubated overnight at $65^{\circ} \mathrm{C}$. The rest of the sonicated solution was mixed with antibody and incubated overnight at $4^{\circ} \mathrm{C}$ with rotation. The antibodies used here were $3 \mu \mathrm{L}$ of mouse monoclonal anti-ßactin (cloneAC15:A1978, Sigma), $2 \mu \mathrm{L}$ of goat polyclonal anti-BAF57 (ab14764, Abcam), $1 \mu \mathrm{L}$ of mouse monoclonal anti-Pol II[8WG16] (ab817, Abcam), $2 \mu \mathrm{L}$ of rabbit IgG (sc2027, Santa Cruz Biotechnology), and $1 \mu \mathrm{L}$ of rabbit polyclonal anti-Histone $\mathrm{H} 3$ (ab1791, Abcam). After antibody reaction, $20 \mu \mathrm{L}$ of dynabeads protein $\mathrm{G}$ (Invitorgen) was added and was rotated for another $6 \mathrm{~h}$ at $4^{\circ} \mathrm{C}$. The bead antibody conjugates were washed in the following order with buffer I, buffer II $(50 \mathrm{mM}$ HEPES at $\mathrm{pH}$ $7.8,500 \mathrm{mM} \mathrm{NaCl}, 1 \mathrm{mM}$ EDTA, $1 \%$ Triton $\mathrm{X}-100,0.1 \%$ sodium deoxycholate, $1 \mathrm{mM}$ DTT, protease inhibitors), buffer III (20 mM Tris- $\mathrm{HCl}$ at $\mathrm{pH} 8.0,1 \mathrm{mM}$ EDTA, $250 \mathrm{mM} \mathrm{LiCl}, 0.5 \%$ NP40, 
$0.5 \%$ sodium deoxycholate, $1 \mathrm{mM} \mathrm{DTT}$, protease inhibitors), and TE containing $1 \mathrm{mM}$ DTT and protease inhibitors for $30 \mathrm{~min}$ at $4^{\circ} \mathrm{C}$ with rotation. After the last washing, $150 \mu \mathrm{L}$ of $1 \times$ Stop buffer with $0.3 \mu \mathrm{g} / \mu \mathrm{L}$ proteinase $\mathrm{K}$ was added to the beads, and cross-links were reversed by incubation overnight at $65^{\circ} \mathrm{C}$. DNA was isolated from inputs and immunoprecipitates. The DNA was finally resuspended in $50 \mu \mathrm{L}$ of elution buffer. Four microliters was used for qPCR analysis. When abundant chromatin proteins like core histones were precipitated, 10 NT oocytes (equivalent to 3000 injected nuclei) were enough to detect signals. However, other cases like nuclear actin required 14-20 NT oocytes (equivalent to 4200-6000 injected nuclei). We used a transgenic ES cell line that possesses $\sim 30$ copies of the Oct 4 regulatory region as a donor cell in order to increase the strength of the signals. The relative abundance of precipitated DNA against total input DNA was measured by qPCR, and this value is expressed as signal per a single gene copy. In every ChIP analysis, anti-histone $\mathrm{H} 3$ antibody was used as a positive control to check whether precipitation was carried out successfully.

\section{Coimmunoprecipitation and immunoprecipitation analysis}

Ten GVs per coimmunoprecipitation were collected in immunoprecipitation buffer (20 mM HEPES at $\mathrm{pH} 7.5,5 \mathrm{mM} \mathrm{KCl}$, $1.5 \mathrm{mM} \mathrm{MgCl}_{2}, 1 \mathrm{mM}$ EGTA, $150 \mathrm{mM} \mathrm{NaCl}, 0.1 \% \mathrm{NP} 40,1 \mathrm{mM}$ DTT, $0.2 \mathrm{mM}$ PMSF, protease inhibitor cocktail). The GVs in $10 \mu \mathrm{L}$ of immunoprecipitation buffer were transferred into tubes and disrupted by pipetting up and down. One microliter was taken as an input, and 1-3 $\mu \mathrm{L}$ of the following antibodies were added: mouse monoclonal anti-GFP (11814460001, Roche), rabbit IgG, goat polyclonal anti-BAF57, rabbit polyclonal antiBAF53A (ab3882, Abcam), rabbit polyclonal anti-BRG1 (A300813A, Bethyl Laboratories), and mouse monoclonal anti-Pol II[8WG16]. After incubating overnight at $4^{\circ} \mathrm{C}$, Dynabeads Protein $\mathrm{G}$ was added and incubated for $30 \mathrm{~min}$ at room temperature. The beads were washed with immunoprecipitation buffer and binding proteins were extracted for Western blots. Immunoprecipitation of Toca-1 from GV extracts was carried out as described previously (Ho et al. 2004) and the extracts were obtained from 50 GVs.

\section{Nuclear actin fractionation}

Thirty GVs were collected in mineral oil in order to minimize artificial changes in actin polymerization. The GVs were transferred into an ultracentrifuge tube and $500 \mu \mathrm{L}$ of lysis and F-actin stabilization buffer (50 mM PIPES at pH 6.9, $50 \mathrm{mM} \mathrm{NaCl}, 5 \mathrm{mM}$ $\mathrm{MgCl}_{2}, 5 \mathrm{mM}$ EGTA, $5 \%$ glycerol, $0.1 \%$ NP40, $0.1 \%$ Triton $\mathrm{X}-100,0.1 \%$ Tween20, $0.1 \% \beta$-mercaptoethanol, 1 mM ATP, protease inhibitor cocktail) was added. GVs were disrupted by pipetting up and down and the lysate was centrifuged at 100,000g for $1 \mathrm{~h}$ at $23^{\circ} \mathrm{C}$. The supernatant was transferred immediately into another tube and was used as the G-actin fraction. The pellet was resuspended in $500 \mu \mathrm{L}$ of ice-cold water containing $100 \mu \mathrm{M} \mathrm{CB}$ and kept on ice for $30 \mathrm{~min}$ with some pipetting. After the incubation, samples were sonicated with probe sonicator and used as the F-actin fraction. Total amounts of $\beta$-actin or total actin were measured by the Western blot analysis.

\section{Western blots}

Western blots were performed following standard protocols. Anti-mouse, anti-rabbit, or anti-goat IgG Alexa Fluor 680 (Invitrogen) was used as a secondary antibody, and bands were detected using the LI-COR ODYSSEY imaging system. Primary antibodies used were as follows: rabbit polyclonal anti-Tocal (a gift from J. Gallop and M. Kirschner), mouse monoclonal anti$\beta$-actin (cloneAC15), rabbit polyclonal anti-actin (A2103, Sigma), rabbit polyclonal anti-Histone H2B (ab1790, Abcam), mouse monoclonal anti-GFP, mouse monoclonal anti-HA (H9658, Sigma), and rabbit polyclonal anti-HA (ab9110, Abcam).

\section{Plasmid construction and RNA synthesis}

Actin mutants (Posern et al. 2002, 2004) were subcloned from original reported vectors into Gateway vectors (pCS2- $\beta$-actin[R62D/S14C/G15S/G13R/wt]-HA). Xenopus tropicalis jmy, X. tropicalis Toca-1 (fnbp11), mouse N-WASP (Wasl), and X. laevis rac1 were cloned into pCS2-HA and/or pCS2-Cherry-HA. pCS2Cherry-hH2B and pCS2-RFP-histoneB4 were produced previously in our laboratory (Jullien et al. 2010). p3216PECMS2 (Janicki et al. 2004), pCS2-GFP-UtrCH (Burkel et al. 2007), and pCMV-CuO-lacI-mCherry-laminB1 (Kumaran and Spector 2008) were gifts. For producing Oct4 regulatory region-Neo cell lines, the p3216PECMS2 plasmid was modified. The inducible CMV promoter was swapped with the murine Oct4 3.6-kb upstream region and the CFP reporter was changed to the Neomycinresistant gene. This plasmid was transfected to ES cells. In vitro synthesized mRNAs were produced with MEGAscript SP6 (AM1330, Ambion).

\section{Statistic analysis}

The number of biological replicates are shown as $n$. In transcriptional assays, technical duplicates were performed on all samples and an average of the duplicate was regarded as the value of one sample. Statistic difference was calculated by $\mathrm{F}$ and $\mathrm{T}$-test $(P<0.05)$. Error bars were represented as standard error.

\section{Acknowledgments}

We thank J. Gallop and M. Kirschner for gifts of TOCA-1 antibody, Toca-1 mutant plasmids, and N-WASP(VCA) plasmids; R. Treisman for actin mutant plasmids; D. Gorlich for Exportin 6 plasmids; W.M. Bement for GFP-UtrCH plasmids; and D. Spector for p3216PECMS2 and lamin B1 plasmids. We also thank J. Gallop, D. Gorlich, R. Halley-Stott, and P. Narbonne for valuable comments on our manuscript. K.M. is supported by the Japan Society for the Promotion of Science (International Research Fellowship Program). This research is supported by a grant from the Wellcome Trust PhD scholarship (081277) to V.P., and a grant from the Wellcome Trust (grant RG54943) to J.J and J.B.G.

\section{References}

Ambrosino C, Tarallo R, Bamundo A, Cuomo D, Franci G, Nassa G, Paris O, Ravo M, Giovane A, Zambrano N, et al. 2010. Identification of a hormone-regulated dynamic nuclear actin network associated with estrogen receptor $\alpha$ in human breast cancer cell nuclei. Mol Cell Proteomics 9: 1352-1367.

Astrand C, Belikov S, Wrange O. 2009. Histone acetylation characterizes chromatin presetting by NF1 and Oct1 and enhances glucocorticoid receptor binding to the MMTV promoter. Exp Cell Res 315: 2604-2615.

Bettinger BT, Gilbert DM, Amberg DC. 2004. Actin up in the nucleus. Nat Rev Mol Cell Biol 5: 410-415.

Bohnsack MT, Stuven T, Kuhn C, Cordes VC, Gorlich D. 2006. A selective block of nuclear actin export stabilizes the giant nuclei of Xenopus oocytes. Nat Cell Biol 8: 257-263.

Boiani M, Eckardt S, Scholer HR, McLaughlin KJ. 2002. Oct4 distribution and level in mouse clones: consequences for pluripotency. Genes Dev 16: 1209-1219. 
Burkel BM, von Dassow G, Bement WM. 2007. Versatile fluorescent probes for actin filaments based on the actin-binding domain of utrophin. Cell Motil Cytoskeleton 64: 822-832.

Byrne JA, Simonsson S, Western PS, Gurdon JB. 2003. Nuclei of adult mammalian somatic cells are directly reprogrammed to oct- 4 stem cell gene expression by amphibian oocytes. Curr Biol 13: 1206-1213.

Cairns BR. 2009. The logic of chromatin architecture and remodelling at promoters. Nature 461: 193-198.

Campellone KG, Welch MD. 2010. A nucleator arms race: cellular control of actin assembly. Nat Rev Mol Cell Biol 11: $237-251$.

Clark TG, Merriam RW. 1977. Diffusible and bound actin nuclei of Xenopus laevis oocytes. Cell 12: 883-891.

Dion V, Shimada K, Gasser SM. 2010. Actin-related proteins in the nucleus: life beyond chromatin remodelers. Curr Opin Cell Biol 22: 383-391.

Eden S, Rohatgi R, Podtelejnikov AV, Mann M, Kirschner MW. 2002. Mechanism of regulation of WAVE1-induced actin nucleation by Rac1 and Nck. Nature 418: 790-793.

Ferrai C, Naum-Ongania G, Longobardi E, Palazzolo M, Disanza A, Diaz VM, Crippa MP, Scita G, Blasi F. 2009. Induction of HoxB transcription by retinoic acid requires actin polymerization. Mol Biol Cell 20: 3543-3551.

Fricke R, Gohl C, Dharmalingam E, Grevelhorster A, Zahedi B, Harden N, Kessels M, Qualmann B, Bogdan S. 2009. Drosophila Cip4/Toca-1 integrates membrane trafficking and actin dynamics through WASP and SCAR/WAVE. Curr Biol 19: 1429-1437.

Gurdon JB, Melton DA. 2008. Nuclear reprogramming in cells. Science 322: 1811-1815.

Halley-Stott RP, Pasque V, Astrand C, Miyamoto K, Simeoni I, Jullien J, Gurdon JB. 2010. Mammalian nuclear transplantation to germinal vesicle stage Xenopus oocytes-a method for quantitative transcriptional reprogramming. Methods 51: 56-65.

Hanna J, Saha K, Pando B, van Zon J, Lengner CJ, Creyghton MP, van Oudenaarden A, Jaenisch R. 2009. Direct cell reprogramming is a stochastic process amenable to acceleration. Nature 462: 595-601.

Ho L, Crabtree GR. 2010. Chromatin remodelling during development. Nature 463: 474-484.

Ho HY, Rohatgi R, Lebensohn AM, Le M, Li J, Gygi SP, Kirschner MW. 2004. Toca-1 mediates Cdc42-dependent actin nucleation by activating the N-WASP-WIP complex. Cell 118: 203-216.

Ho L, Ronan JL, Wu J, Staahl BT, Chen L, Kuo A, Lessard J, Nesvizhskii AI, Ranish J, Crabtree GR. 2009. An embryonic stem cell chromatin remodeling complex, esBAF, is essential for embryonic stem cell self-renewal and pluripotency. Proc Natl Acad Sci 106: 5181-5186.

Hofmann WA, Stojilikovic L, Fuchsova B, Vargas GM, Mavrommatis E, Philimonenko V, Kysela K, Goodrich JA, Lessard JL, Hope TJ, et al. 2004. Actin is part of pre-initiation complexes and is necessary for transcription by RNA polymerase II. Nat Cell Biol 6: 1094-1101.

Hu P, Wu S, Hernandez N. 2004. A role for $\beta$-actin in RNA polymerase III transcription. Genes Dev 18: 3010-3015.

Jaenisch R, Young R. 2008. Stem cells, the molecular circuitry of pluripotency and nuclear reprogramming. Cell 132: 567-582.

Janicki SM, Tsukamoto T, Salghetti SE, Tansey WP, Sachidanandam R, Prasanth KV, Ried T, Shav-Tal Y, Bertrand E, Singer RH, et al. 2004. From silencing to gene expression: real-time analysis in single cells. Cell 116: 683-698.

Jullien J, Astrand C, Halley-Stott RP, Garrett N, Gurdon JB. 2010. Characterization of somatic cell nuclear reprogram- ming by oocytes in which a linker histone is required for pluripotency gene reactivation. Proc Natl Acad Sci 107: 5483-5488.

Kidder BL, Palmer S, Knott JG. 2009. SWI/SNF-Brg1 regulates self-renewal and occupies core pluripotency-related genes in embryonic stem cells. Stem Cells 27: 317-328.

Kim JB, Sebastiano V, Wu G, Arauzo-Bravo MJ, Sasse P, Gentile L, Ko K, Ruau D, Ehrich M, van den Boom D, et al. 2009. Oct4-induced pluripotency in adult neural stem cells. Cell 136: 411-419.

Kim K, Doi A, Wen B, Ng K, Zhao R, Cahan P, Kim J, Aryee MJ, Ji H, Ehrlich LI, et al. 2010. Epigenetic memory in induced pluripotent stem cells. Nature 467: 285-290.

Kumaran RI, Spector DL. 2008. A genetic locus targeted to the nuclear periphery in living cells maintains its transcriptional competence. J Cell Biol 180: 51-65.

Lund E, Paine PL. 1990. Nonaqueous isolation of transcriptionally active nuclei from Xenopus oocytes. Methods Enzymol 181: $36-43$.

McDonald D, Carrero G, Andrin C, de Vries G, Hendzel MJ. 2006. Nucleoplasmic $\beta$-actin exists in a dynamic equilibrium between low-mobility polymeric species and rapidly diffusing populations. J Cell Biol 172: 541-552.

Mikkelsen TS, Hanna J, Zhang X, Ku M, Wernig M, Schorderet P, Bernstein BE, Jaenisch R, Lander ES, Meissner A. 2008. Dissecting direct reprogramming through integrative genomic analysis. Nature 454: 49-55.

Murata K, Kouzarides T, Bannister AJ, Gurdon JB. 2010. Histone $\mathrm{H} 3$ lysine 4 methylation is associated with the transcriptional reprogramming efficiency of somatic nuclei by oocytes. Epigenetics Chromatin 3: 4. doi: 10.1186/1756-8935-3-4.

Olave IA, Reck-Peterson SL, Crabtree GR. 2002. Nuclear actin and actin-related proteins in chromatin remodeling. Annu Rev Biochem 71: 755-781.

Pasque V, Miyamoto K, Gurdon JB. 2010. Efficiencies and mechanisms of nuclear reprogramming. Cold Spring Harb Symp Quant Biol doi: 101101/sqb.2010.75.002.

Percipalle P. 2009. The long journey of actin and actin-associated proteins from genes to polysomes. Cell Mol Life Sci 66: 2151-2165.

Philimonenko VV, Zhao J, Iben S, Dingova H, Kysela K, Kahle M, Zentgraf $\mathrm{H}$, Hofmann WA, de Lanerolle P, Hozak P, et al. 2004. Nuclear actin and myosin I are required for RNA polymerase I transcription. Nat Cell Biol 6: 1165-1172.

Posern G, Sotiropoulos A, Treisman R. 2002. Mutant actins demonstrate a role for unpolymerized actin in control of transcription by serum response factor. Mol Biol Cell 13: 4167-4178.

Posern G, Miralles F, Guettler S, Treisman R. 2004. Mutant actins that stabilise F-actin use distinct mechanisms to activate the SRF coactivator MAL. EMBO I 23: 3973-3983.

Rando OJ, Zhao K, Janmey P, Crabtree GR. 2002. Phosphatidylinositol-dependent actin filament binding by the SWI/SNFlike BAF chromatin remodeling complex. Proc Natl Acad Sci 99: 2824-2829.

Scheer U, Hinssen H, Franke WW, Jockusch BM. 1984. Microinjection of actin-binding proteins and actin antibodies demonstrates involvement of nuclear actin in transcription of lampbrush chromosomes. Cell 39: 111-122.

Simonsson S, Gurdon J. 2004. DNA demethylation is necessary for the epigenetic reprogramming of somatic cell nuclei. Nat Cell Biol 6: 984-990.

Singhal N, Graumann J, Wu G, Arauzo-Bravo MJ, Han DW, Greber B, Gentile L, Mann M, Scholer HR. 2010. Chromatinremodeling components of the BAF complex facilitate reprogramming. Cell 141: 943-955. 
Smith ZD, Nachman I, Regev A, Meissner A. 2010. Dynamic single-cell imaging of direct reprogramming reveals an early specifying event. Nat Biotechnol 28: 521-526.

Stadtfeld M, Maherali N, Breault DT, Hochedlinger K. 2008. Defining molecular cornerstones during fibroblast to iPS cell reprogramming in mouse. Cell Stem Cell 2: 230-240.

Stuven T, Hartmann E, Gorlich D. 2003. Exportin 6: a novel nuclear export receptor that is specific for profilin.actin complexes. EMBO I 22: 5928-5940.

Takahashi K, Yamanaka S. 2006. Induction of pluripotent stem cells from mouse embryonic and adult fibroblast cultures by defined factors. Cell 126: 663-676.

Tamada H, Van Thuan N, Reed P, Nelson D, Katoku-Kikyo N, Wudel J, Wakayama T, Kikyo N. 2006. Chromatin decondensation and nuclear reprogramming by nucleoplasmin. Mol Cell Biol 26: 1259-1271.

Taylor MD, Sadhukhan S, Kottangada P, Ramgopal A, Sarkar K, D'Silva S, Selvakumar A, Candotti F, Vyas YM. 2010. Nuclear role of WASp in the pathogenesis of dysregulated TH1 immunity in human Wiskott-Aldrich syndrome. Sci Transl Med 2: 37-44.

Vartiainen MK, Guettler S, Larijani B, Treisman R. 2007. Nuclear actin regulates dynamic subcellular localization and activity of the SRF cofactor MAL. Science 316: 17491752.

Visa N, Percipalle P. 2010. Nuclear functions of actin. Cold Spring Harb Perspect Biol 2: a000620. doi: 10.101/cshperspect. a000620.

Wu X, Yoo Y, Okuhama NN, Tucker PW, Liu G, Guan JL. 2006. Regulation of RNA-polymerase-II-dependent transcription by N-WASP and its nuclear-binding partners. Nat Cell Biol 8: 756-763.

$\mathrm{Xu}$ YZ, Thuraisingam T, Morais DA, Rola-Pleszczynski M, Radzioch D. 2010. Nuclear translocation of $\beta$-actin is involved in transcriptional regulation during macrophage differentiation of HL-60 cells. Mol Biol Cell 21: 811-820.

Yamanaka S. 2009. Elite and stochastic models for induced pluripotent stem cell generation. Nature 460: 49-52.

Zhao K, Wang W, Rando OJ, Xue Y, Swiderek K, Kuo A, Crabtree GR. 1998. Rapid and phosphoinositol-dependent binding of the SWI/SNF-like BAF complex to chromatin after T lymphocyte receptor signaling. Cell 95: 625-636.

Zuchero JB, Coutts AS, Quinlan ME, Thangue NB, Mullins RD. 2009. p53-cofactor JMY is a multifunctional actin nucleation factor. Nat Cell Biol 11: 451-459. 


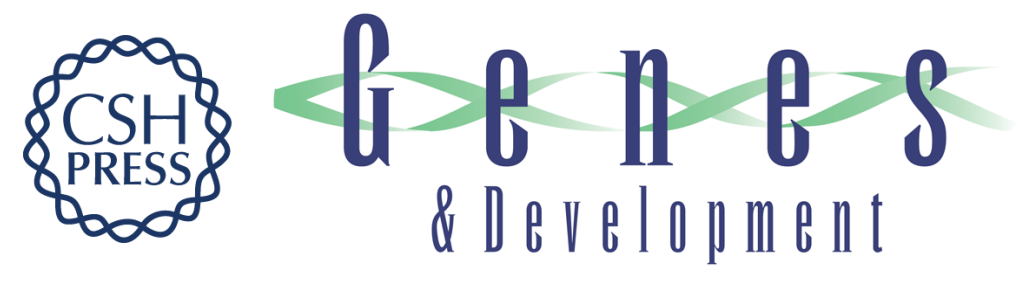

\section{Nuclear actin polymerization is required for transcriptional reprogramming of Oct4 by oocytes}

Kei Miyamoto, Vincent Pasque, Jerome Jullien, et al.

Genes Dev. 2011, 25:

Access the most recent version at doi:10.1101/gad.615211

Supplemental
Material $\quad$ http://genesdev.cshlp.org/content/suppl/2011/04/22/25.9.946.DC1

References This article cites 55 articles, 16 of which can be accessed free at: http://genesdev.cshlp.org/content/25/9/946.full.html\#ref-list-1

License Freely available online through the Genes \& Development Open Access option.

Email Alerting Receive free email alerts when new articles cite this article - sign up in the box at the top Service right corner of the article or click here.

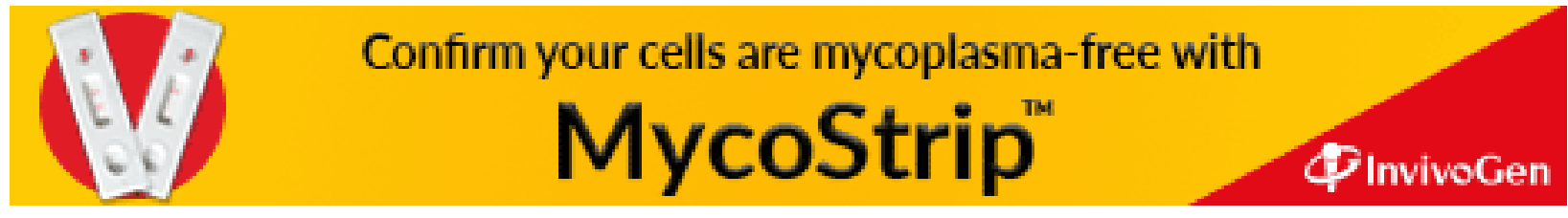

